\title{
Review on optofluidic microreactors for artificial photosynthesis
}

\author{
Xiaowen Huang ${ }^{1,2,3}$, Jianchun Wang ${ }^{1}$, Tenghao $\mathrm{Li}^{2,3}$, Jianmei Wang ${ }^{1}$, Min Xu${ }^{1}$, \\ Weixing $\mathrm{Yu}^{4}$, Abdel El Abed ${ }^{5}$ and Xuming Zhang ${ }^{*} 2,3, \S$
}

\author{
Review

\section{Address:} \\ ${ }^{1}$ Energy Research Institute, Shandong Academy of Sciences, Jinan, \\ Shandong 250014, China, ${ }^{2}$ Department of Applied Physics, The Hong \\ Kong Polytechnic University, Hong Kong, China, ${ }^{3}$ The Hong Kong \\ Polytechnic University Shenzhen Research Institute, Shenzhen \\ 518057, China, ${ }^{4}$ Key Laboratory of Spectral Imaging Technology, \\ Xi'an Institute of Optics and Precision Mechanics, Chinese Academy \\ of Sciences, Xi'an, Shaanxi 710119, China, and 5 Laboratoire de \\ Photonique Quantique et Moléculaire, UMR 8537, Ecole Normale \\ Supérieure de Cachan, CentraleSupélec, CNRS, Université \\ Paris-Saclay, 61 avenue du Président Wilson, 94235 Cachan, France \\ Email: \\ Xuming Zhang* - apzhang@polyu.edu.hk \\ * Corresponding author \\ $\S$ Tel.: +852-34003258; Fax: +852-23337629 \\ Keywords: \\ artificial photosynthesis; carbon dioxide fixation; coenzyme \\ regeneration; microfluidics; optofluidics; water splitting
}

Beilstein J. Nanotechnol. 2018, 9, 30-41. doi:10.3762/bjnano.9.5

Received: 20 July 2017

Accepted: 06 December 2017

Published: 04 January 2018

This article is part of the Thematic Series "Energy conversion, storage and environmental remediation using nanomaterials".

Guest Editor: W.-J. Ong

(C) 2018 Huang et al.; licensee Beilstein-Institut. License and terms: see end of document.

\footnotetext{
Abstract

Artificial photosynthesis (APS) mimics natural photosynthesis (NPS) to store solar energy in chemical compounds for applications such as water splitting, $\mathrm{CO}_{2}$ fixation and coenzyme regeneration. NPS is naturally an optofluidic system since the cells (typical size 10 to $100 \mu \mathrm{m}$ ) of green plants, algae, and cyanobacteria enable light capture, biochemical and enzymatic reactions and the related material transport in a microscale, aqueous environment. The long history of evolution has equipped NPS with the remarkable merits of a large surface-area-to-volume ratio, fast small molecule diffusion and precise control of mass transfer. APS is expected to share many of the same advantages of NPS and could even provide more functionality if optofluidic technology is introduced. Recently, many studies have reported on optofluidic APS systems, but there is still a lack of an in-depth review. This article will start with a brief introduction of the physical mechanisms and will then review recent progresses in water splitting, $\mathrm{CO}_{2}$ fixation and coenzyme regeneration in optofluidic APS systems, followed by discussions on pending problems for real applications.
} 


\section{Review \\ Introduction}

The emerging energy crisis, the greenhouse effect and food shortage are devastating problems to be solved, and artificial photosynthesis (APS) is considered to be the most promising and viable method [1-9]. As the name implies, APS is the human replication of natural photosynthesis (NPS). NPS is a very important process in plants and other organisms which utilize sunlight, water and $\mathrm{CO}_{2}$ to synthesize energy-rich carbohydrates $[10,11]$. The chloroplast is the place where NPS occurs. To clearly introduce this organelle, progressively smaller structures (plant cell, chloroplast, thylakoid membrane) of a general leaf are shown in Figure 1A-D. Each chloroplast (Figure 1C) contains numerous thylakoids. On the thylakoid membrane, the natural light-harvesting antenna complexes, photosystem II (PS II, P680) and photosystem I (PS I, P700), capture the photons and regenerate the coenzyme for carbohydrates synthesis (Figure 1D). However, in APS, sunlight is used to create not only the carbohydrates but also other highvalue chemicals from abundant resources [12-21].

Based on the targeted production, three key areas in the field of APS have attracted intense attention including: photocatalytic water splitting [24,25], light-driven $\mathrm{CO}_{2}$ reduction [26] and photo-coenzyme regeneration [27] (see Figure 2), which are promising solutions to the energy crisis, greenhouse effect and food shortage, respectively [24,26,28-45].

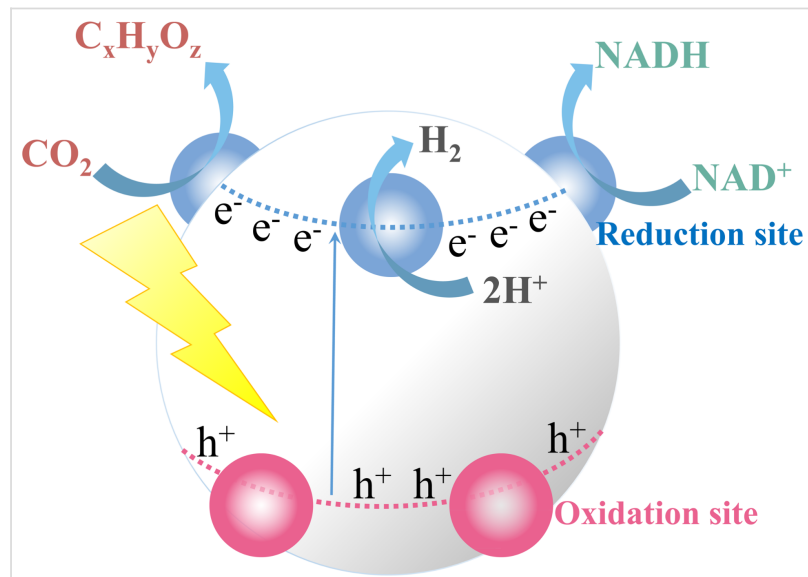

Figure 2: Basic principles and reactions in artificial photosynthesis, in which the processes of water splitting, $\mathrm{CO}_{2}$ reduction and coenzyme regeneration all utilize electrons on the reduction site.
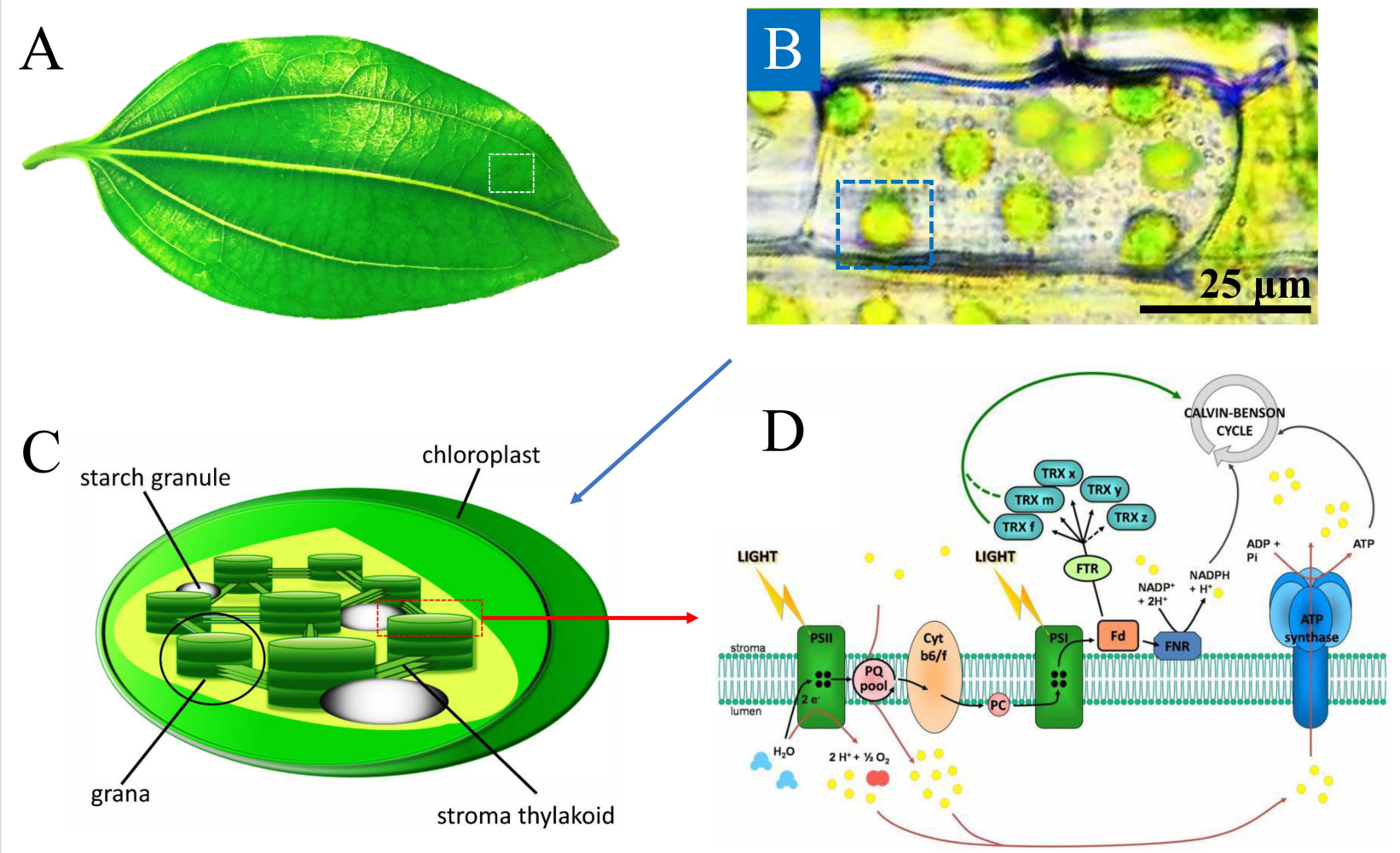

Figure 1: (A) A typical plant leaf. (B) Chloroplasts inside the plant cells. The average size of the chloroplasts is $6 \mu \mathrm{m}$ (ranging from 3 to $10 \mu \mathrm{m}$ ). (C) Plant cell chloroplast structure. Adapted from [22], copyright BioMed Central Ltd. 2014. (D) Thylakoid membrane containing photosystem II reaction centers P680 and photosystem I reaction centers P700. Adapted from [23], copyright 2013 Michelet, Zaffagnini, Morisse, Sparla, Pérez-Pérez, Francia, Danon, Marchand, Fermani, Trost, and Lemaire. 
Photocatalytic water splitting aims to convert water into hydrogen and oxygen. Some studies have focused on only the halfreaction for water splitting, while ignoring the other half-reaction for oxygen production. This is often called photocatalytic hydrogen production (or generation) and can be regarded as a low-configured version of photocatalytic water splitting. As a renewable and nontoxic gas, hydrogen works not only as a clean fuel but also as a feedstock for important chemical production, such as ammonia and methanol. Similarly, light-driven $\mathrm{CO}_{2}$ reduction has great potential as a clean fuel supplier, especially for the production of methanol or methane [45,46]. Additionally, with the consumption of $\mathrm{CO}_{2}$, APS possibly provides a solution to the greenhouse effect and global warming. Unlike human beings, plants have no need to use $\mathrm{CO}_{2}$ as a clean fuel or for to reduce the greenhouse effect. They simply "consume" $\mathrm{CO}_{2}$ to produce carbohydrates (e.g., sugar, cellulose). The global demand for food is increasing dramatically with the continuous growth of the world population [47]. An increase in population requires more land, water and energy, which in turn decreases the ability to produce food. Meanwhile, the requirement for more land results in the destruction of an increased area of forests, further disrupting the climate change and the greenhouse effect. Thus, in a global perspective, the energy crisis, climate change, greenhouse effect, air pollution and food shortage are interconnected. Food production in the form of crops relies on the famous Calvin cycle, in which the coenzymes - nicotinamide adenine dinucleotide hydride (NADH) and nicotinamide adenine dinucleotide phosphate hydride (NADPH) - play an important role since they work as the reducing power for the biosynthetic reactions. Despite its advantages, NPS still has a very low energy conversion efficiency (typically $<1 \%$ ) to capture sunlight and $\mathrm{CO}_{2}$ for the production of carbohydrates, even after billions of years of evolution, and it is far from its theoretical limit of $30 \%$ [48]. This gives great room to develop an improved scientific solution to produce basic food materials with high energy efficiency while circumventing all the problems.

Optofluidic technology has recently exploded with new concepts to enable fine control of light and liquids in microscale structures [39-41]. In fact, NPS is naturally an optofluidic system as it is carried out in microscale organisms (chloroplasts) filled with fluids (see Figure 1), inferring the feasibility to be mimicked by man-made optofluidic structures. Optofluidics can promote the reaction efficiencies due to its advantages such as large surface-area-to-volume ratio [40], fast reaction rate, high-precision manipulation [38], easy flow control and improved mass and photon transfer in the reaction system [4953]. The small volume of optofluidic systems reduces the diffusion time, dramatically increases the reaction rate on the photocatalyst surface, and reduces the consumption of expensive photocatalysts and enzymes. Therefore, this platform is also useful for the rapid screening of various photocatalysts [54-59]. Inexpensive, parallel tests are beneficial for the rare or expensive chemical reactions, too $[60,61]$. Moreover, for enzymatic reactions, the flow-based reaction has the great advantage of avoiding product inhibition and cross-reaction [42]. Furthermore, cascaded reactions can be divided into different areas where each region can be set with their own optimal reaction conditions such as temperature, $\mathrm{pH}$ and concentration. The various photocatalytic nanomaterials [62] can be designed in different forms in the microreactor inside the optofluidic device, such as in the form of immobilized nanoparticles, films, plugs, droplets, etc.

Fortunately, many works have contributed to the field of APS. The research efforts have mostly focus on aspects such as development of novel catalytic materials, modification of the existed catalytic materials (e.g., noble-gas doping, co-catalyst impregnation, noble-metal loading, plasmonic sensitization and Z-scheme systems), and optofluidics (or microfluidics) based APS.

It should be noted that many efforts have been made to develop bio-photoreactors to culture microorganisms to produce microalgae, bioenergy and biomass [63]. Broadly speaking, these bio-photoreactors also belong to optofluidics-based APS, but they are not covered in this article since many of them use large reactors and are thus not related to microstructures.

The following review will start with a brief introduction on the mechanisms of photocatalysis-based APS (water splitting, $\mathrm{CO}_{2}$ reduction and coenzyme regeneration). Then we will introduce the representative designs of these three areas with an emphasis on how they help solve the existing problems in their respective area. Finally, we conclude with a discussion of the technical barriers that hinder their practical application.

\section{Basic mechanisms of artificial photosynthesis}

The APS reaction is not a spontaneous reaction, for example, the Gibbs free energy in water splitting increases by $237 \mathrm{~kJ} \cdot \mathrm{mol}^{-1}$, and the required energy could be offered by external light. In principle, a semiconductor photocatalyst (e.g., $\left.\mathrm{TiO}_{2}, \mathrm{C}_{3} \mathrm{~N}_{4}\right)$ absorbs the appropriate photon $\left(h v \geq E_{0}\right.$, where $E_{0}$ is the bandgap of the semiconductor photocatalyst) to excite an electron in the conduction band, leaving a hole in the valence band. The electron moves to the surface-active sites for surface redox reactions [64]. The activation equations for water splitting, $\mathrm{CO}_{2}$ photoreduction and coenzyme regeneration are as follows:

$$
\mathrm{SC}+h v \rightarrow \mathrm{SC}\left(\mathrm{e}_{\mathrm{cb}}{ }^{-}+\mathrm{h}_{\mathrm{vb}}{ }^{-}\right)
$$




$$
\begin{gathered}
2 \mathrm{H}_{2} \mathrm{O}+4 \mathrm{~h}^{+} \rightarrow 4 \mathrm{H}^{+}+\mathrm{O}_{2} \\
2 \mathrm{H}^{+}+2 \mathrm{e}^{-} \rightarrow \mathrm{H}_{2} \\
\mathrm{CO}_{2}+6 \mathrm{H}^{+}+6 \mathrm{e}^{-} \rightarrow \mathrm{CH}_{3} \mathrm{OH}+\mathrm{H}_{2} \mathrm{O} \\
\mathrm{CH}_{3} \mathrm{OH}+2 \mathrm{CO} \rightarrow \mathrm{CH}_{3} \mathrm{CHO}+\mathrm{CO}_{2} \\
\mathrm{CH}_{3} \mathrm{OH}+\mathrm{CO}_{2}+2 \mathrm{H}^{+}+2 \mathrm{e}^{-} \rightarrow \mathrm{HCOOCH}_{3}+\mathrm{H}_{2} \mathrm{O} \\
\mathrm{HCOOCH}+\mathrm{CO} \rightarrow \mathrm{CH}_{3} \mathrm{CHO}_{3}+\mathrm{CO}_{2} \\
\mathrm{HCOOCH}_{3}+4 \mathrm{H}^{+}+4 \mathrm{e}^{-} \rightarrow 2 \mathrm{CH}_{3} \mathrm{OH} \\
\mathrm{H}_{2} \mathrm{O}+\mathrm{CO} \rightarrow \mathrm{H}_{2}+\mathrm{CO}_{2} \\
\mathrm{NAD}^{+}+\mathrm{H}^{+}+2 \mathrm{e}^{-} \rightarrow \mathrm{NADH}^{2}
\end{gathered}
$$

Equation 1 represents the formation of the electron-hole pair. Equation 2 and Equation 3 describe the water splitting process. Equations 4-9 present the $\mathrm{CO}_{2}$ reduction processes and Equation 10 is the typical $\mathrm{NAD}^{+}$regeneration. For clearly uncovering the chemical mechanism from the reactants to products, some intermediate processes are reasonably ignored.

All these three items (i.e., water splitting, $\mathrm{CO}_{2}$ reduction and coenzyme regeneration) utilize the electrons on the reduction site, as shown in Figure 2. However, recombination of photoexcited electrons and holes may occur. Even after the electrons are moved to the surface of photocatalysts, some of them would be wasted due to recombination if the electrons are not used immediately for the redox reactions [65-67].

The desirable features of a photocatalyst include wide-range absorption, long-term stability, fast electron-hole separation, and strong redox powers. However, it is difficult to have all of these features in a single photocatalyst. Thereby, a simple heterojunction of two or more photocatalysts and artificial Z-scheme photocatalytic systems have been developed [68] Figure $3 \mathrm{~A}$ shows the charge carrier transfer in a heterojunctiontype photocatalytic system, in which the photo-generated electrons and holes are separated in space to suppress the undesirable recombination. However, when the charge carriers are transferred to lower potentials, the redox ability of these electrons and holes is weakened. Then, another type of photocatalytic system is explored, as shown in Figure 3B. The electron acceptor/donor (A/D) pair is introduced to form the Z-scheme system, known as the PS-A/D-PS system. Since the electron acceptor (A) can react with both the photogenerated electron in PS I and PS II, the electron donor (D) can react with both the photogenerated hole in PS I and PS II, and backward reactions would occur, leading to a significant waste of photogenerated electrons and holes. In another design, the A/D pair is replaced by the conductor (C) to form the PS-C-PS system, as shown in Figure 3C. The inserted conductor acts as the electron mediator and forms the ohmic contact with low contact resistance between PS II and PS I. Through the ohmic contact, the photogenerated electrons from PS II directly recombine with the photogenerated holes from PS I, reducing the electron transfer distance and avoiding the backward reaction in the PS-A/D-PS system. Another simpler design using the solid-solid contact (PS-PS system) is illustrated in Figure 3D. On the contact interface, many defects are easily aggregated, causing the energy levels to be quasi-continuous for the ohmic contact. Besides, the biomimetic or bioinspired strategy showed the most interesting results. Zhou et al. reported a light-harvesting antenna-network inspired polymeric semiconductor-based hybrid nano-system in which water and $\mathrm{CO}_{2}$ were catalyzed to form $\mathrm{H}_{2}$ and $\mathrm{CO}$ in this integrated system [66]. Jiang et al. showed a thylakoid-inspired multishell g- $\mathrm{C}_{3} \mathrm{~N}_{4}$ nanocapsule with orderly stacked nanostructures, which exhibited enhanced visible-light harvesting and electron-transfer properties for high-efficiency photocatalysis [67].

In summary, the basic mechanism of APS is comprised of three processes: (1) generation of charge carriers (i.e., electrons and holes), (2) separation and transfer of charge carriers, and (3) chemical reactions between surface species and charge carriers. Based on this mechanism, various materials have been developed to improve the photocatalytic efficiency [69-72]. Furthermore, by taking advantage of the properties of optofluidics, many studies with interesting improvements have been reported. We will now review these in terms of water splitting, $\mathrm{CO}_{2}$ reduction and coenzyme regeneration.

\section{Microreactors for artificial photosynthesis}

An optofluidic microreactor is a versatile platform for combining new materials and characterizing their reaction kinetics without expensive bulky setups. Recent developments in optofluidics has allowed for the advancement of APS technology by use of the microreactors.

\section{Water splitting}

In the early studies on optofluidic-based water splitting, the optofluidic device often employed sol-gel catalysts on planar channels. For example, Erickson et al. demonstrated a planar setup with $\mathrm{TiO}_{2}-\mathrm{Pt}$ to process the water splitting reaction [73]. 

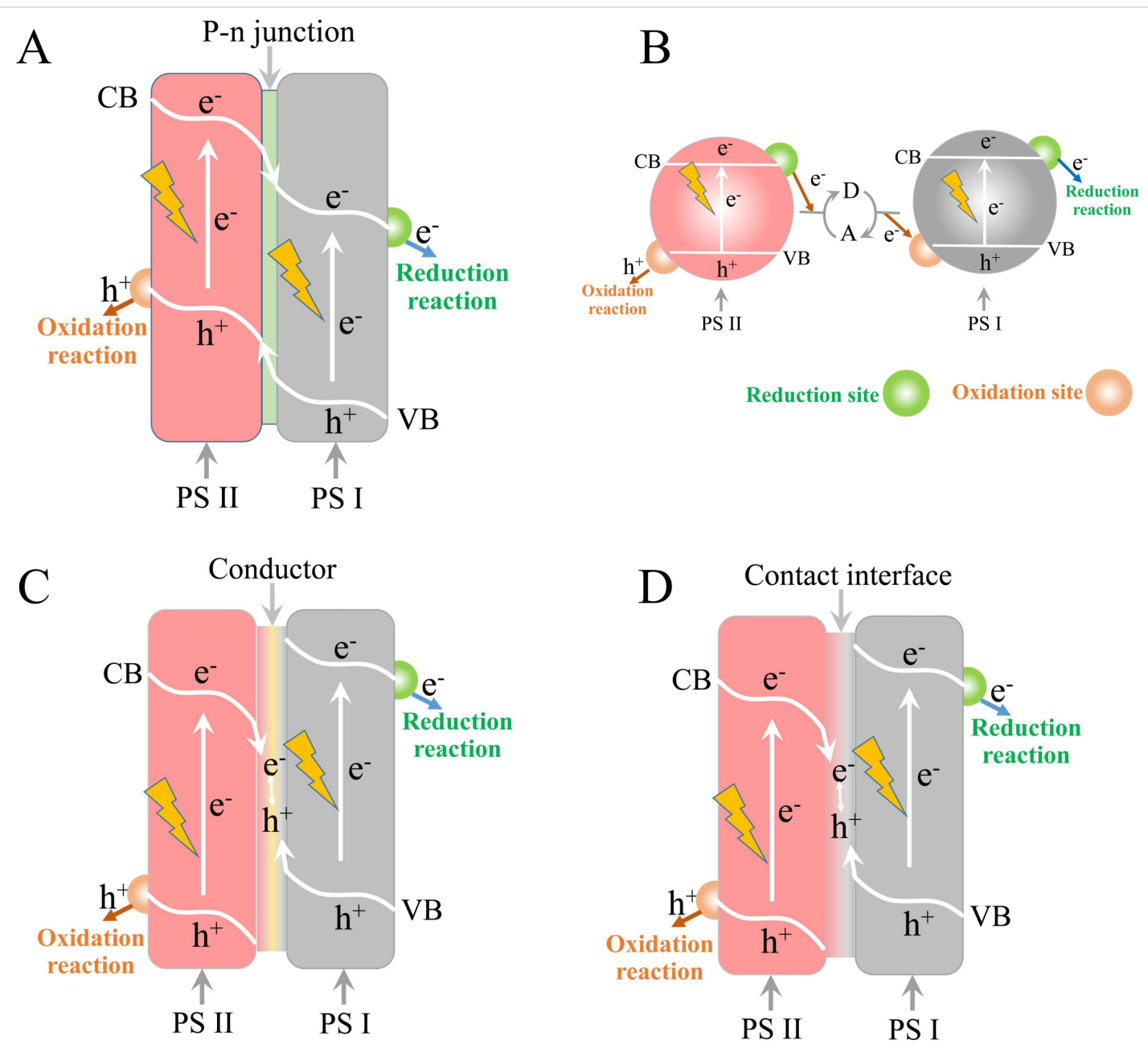

Figure 3: Schematic diagrams of heterojunction and Z-scheme systems. Transfer of charge carriers in (A) the heterojunction-type photocatalytic system, (B) the Z-scheme PS-A/D-PS system, (C) the Z-scheme PS-C-PS system, and (D) the Z-scheme electron PS-PS system. Adapted from [68], copyright 2014 Wiley-VCH Verlag GmbH \& Co. KGaA. PS stands for photosystem.

The reaction was mediated by $\mathrm{I}^{-} / \mathrm{IO}_{3}{ }^{-}$redox pairs, belonging to the PS-A/D-PS system. After the reaction, the optofluidic device showed $\approx 2$-fold improvement in the reaction rates as compared to the traditional bulk method. Nevertheless, this planar design still showed an unsatisfactory performance of hydrogen generation due to a limited active surface area and low mass transfer rate. In another work, Wang et al. proposed an optofluidic microreactor with staggered micropillars in the reaction microchamber [74], as shown in Figure 4. Such structure has four favorable features: (1) enlarged surface area for loading catalysts; (2) perturbation to the liquid flow for rapid mixing; (3) shortened transfer length and enhanced mass transfer; and (4) increased active surface area. With these advantages, the reaction rate could be increased by $56 \%$ as compared to the conventional planar microreactors.

However, a new problem emerges: the direct coating methods are unable to load catalysts firmly and uniformly on the PDMS substrate. Zhang et al. proposed a new casting transfer method for loading catalysts on the PDMS substrate [36], as shown in Figure 5. This method exhibited critically higher durability and better hydrogen production rate than the conventional ones.

\section{$\mathrm{CO}_{2}$ reduction}

Optofluidic microreactors have been firstly applied for water purification [50], water splitting [73], photocatalytic fuel cells [75] and then $\mathrm{CO}_{2}$ reduction [76]. Chen et al. combined the optofluidics with the $\mathrm{TiO}_{2}$ /carbon paper composite membrane for the photoreduction of $\mathrm{CO}_{2}$ [76], as shown in Figure 6. Using this device, they studied the factors that affected the methanol yield (such as flow rate, light intensity and catalyst loading) and obtained a high reduction result in comparison to the reported data. Other membrane-based reactors were reported as well, for instance, mesoporous $\mathrm{CdS} / \mathrm{TiO}_{2} / \mathrm{SBA}-15 @$ carbon paper composite membranes [77] and copper-decorated $\mathrm{TiO}_{2}$ nanorod thin films [78]. 
A

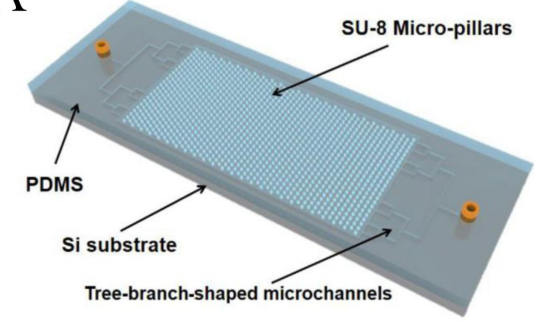

B

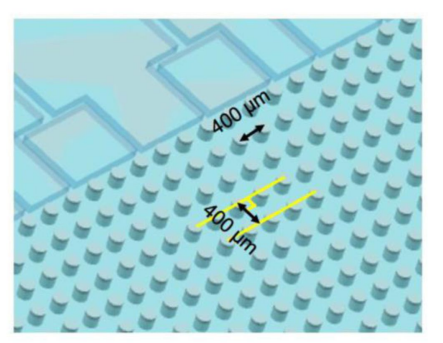

C

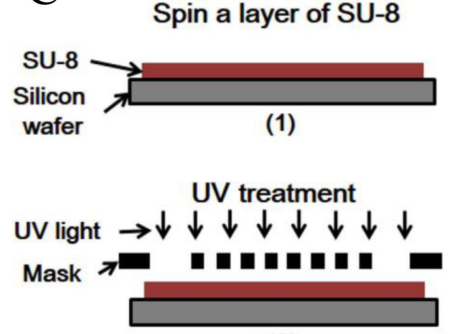

(2)

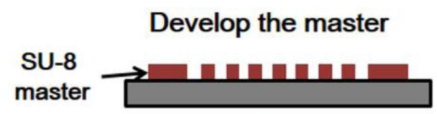

(3)

Coating catalysts on the master

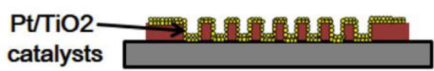

(4)

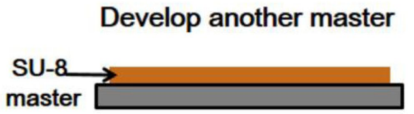

Pour PDMS and cure

PDMS

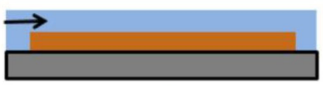

(5)

Peel off the PDMS

(6)

Bonding

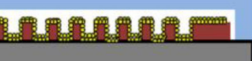

(7)

Figure 4: (A) Schematic of the high-surface-area optofluidic microreactor with micropillar structure. (B) Staggered micropillars in the reaction chamber. (C) Fabrication procedure of the optofluidic microreactor with the catalyst-coated micropillars. Reprint with the permission from [74], copyright 2014 Elsevier Ltd.

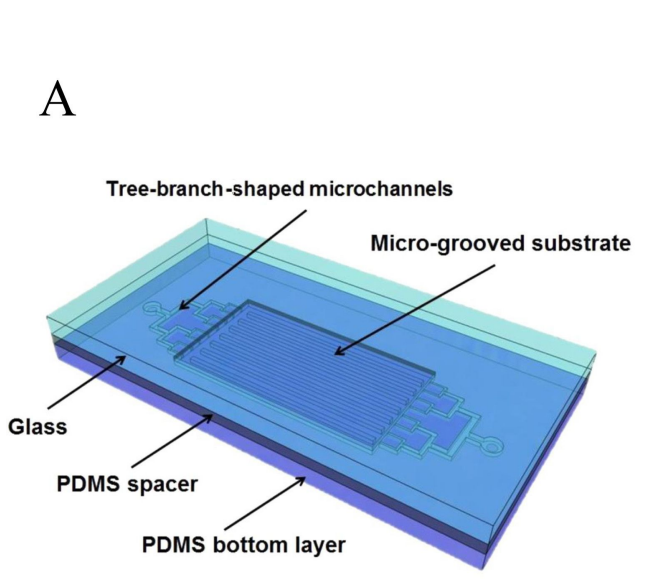

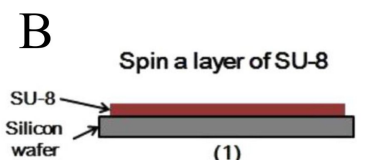

(1)

UV treatment

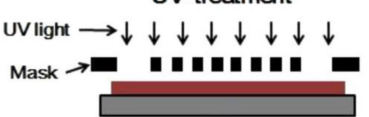

(2)

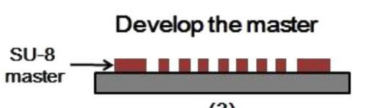

(3)

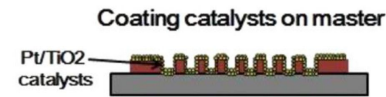

(4)

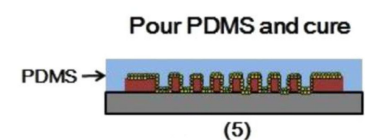

Peeloff the PDMS

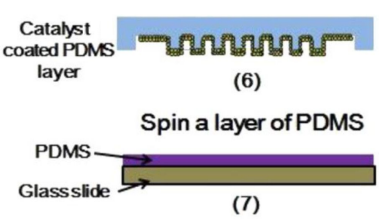

Open a window at the center of PDMS

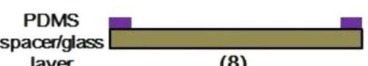

layer (8)

Assembling and bonding

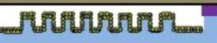

(9)

Figure 5: (A) Schematic of the high-surface-area optofluidic microreactor with micro-grooved structure. (B) Fabrication procedure of the optofluidic microreactor with the catalysts on the PDMS substrate. Adapted from [36], copyright 2015 Elsevier Ltd.

In addition to the PDMS/PMMA-based microchannel reactors, bacterium has been shown to be a good microreactor as well. Yang et al. developed a hybrid approach that combined highly efficient light harvesting of inorganic semiconductors with biocatalysts [79]. As shown in Figure 7, they induced a nonphotosynthetic bacterium with biologically precipitated CdS nanoparticles, enabling the photosynthesis of acetic acid from $\mathrm{CO}_{2}$. The $\mathrm{CdS}$ nanoparticles functioned as the light harvester.
This self-augmented biological system selectively produced acetic acid continuously over several days, demonstrating a novel $\mathrm{CO}_{2}$ reduction microreactor.

\section{Coenzyme regeneration}

APS-based coenzyme regeneration has attracted less attention as compared to water splitting and $\mathrm{CO}_{2}$ reduction [80], but significant progress had already been made before it was combined 


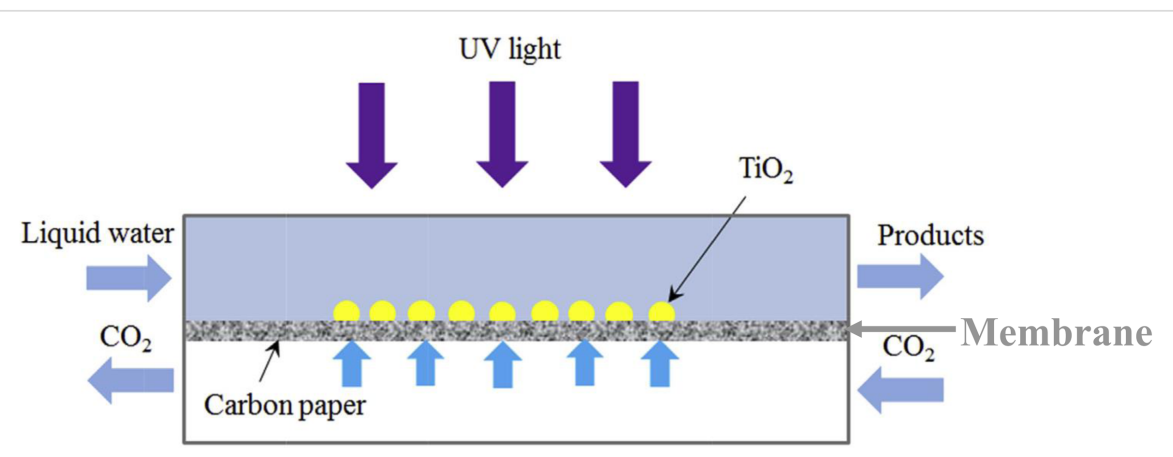

Figure 6: Schematic of the optofluidic membrane microreactor for photocatalytic $\mathrm{CO}_{2}$ reduction. Adapted from [76], copyright 2016 Elsevier Ltd.

A

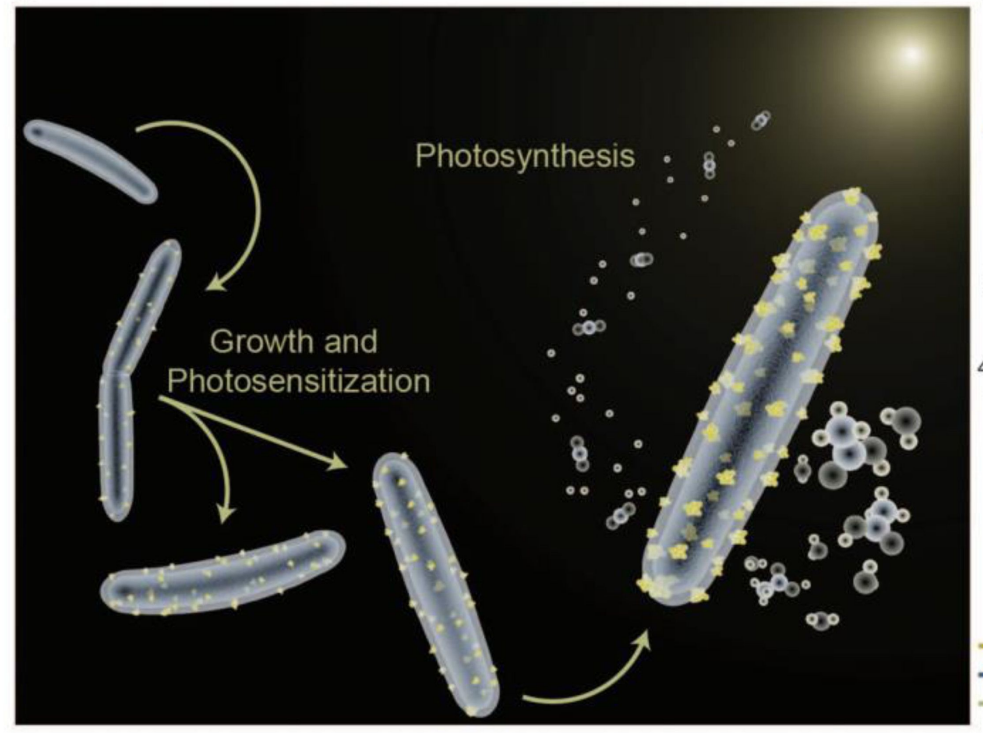

$\mathrm{B}$

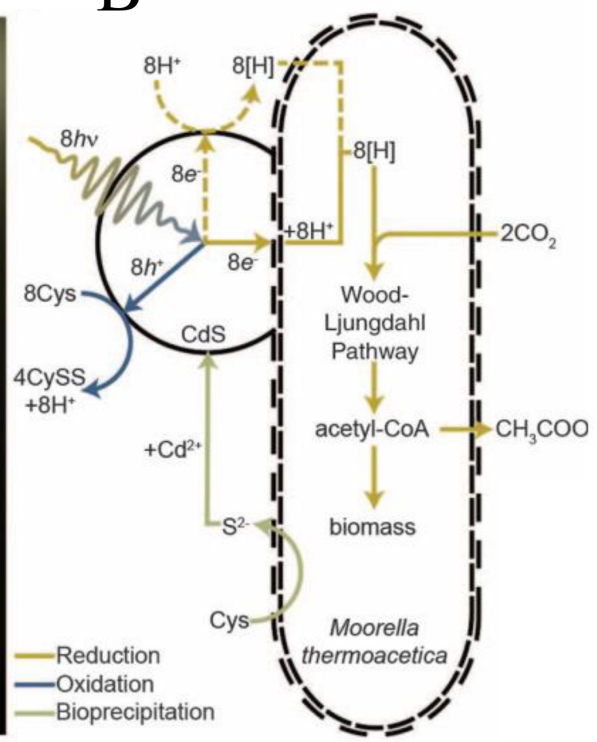

Figure 7: (A) Bacterium-CdS hybrid system that has CdS nanoparticles on the bacterium membrane (yellow particles). (B) Pathway diagram for the light harvesting and the photosynthetic conversion of $\mathrm{CO}_{2}$ to acetic acid with the bacterial enzyme system. Adapted from [79], copyright 2016 American Association for the Advancement of Science.

with the optofluidics [81]. Park et al. developed CdS quantumdot-sensitized $\mathrm{TiO}_{2}$ nanotube arrays for the photo-regeneration of nicotinamide cofactors [82]. They also used $\mathrm{SiO}_{2}$-supported CdS quantum dots for sustainable NADH regeneration [83] However, the toxicity and photoinduced instability of $\mathrm{CdS}$ limited the application of this material. Liu et al. used carbon nitride $\left(\mathrm{C}_{3} \mathrm{~N}_{4}\right)$, a stable and environmental friendly material [84], for NADH regeneration [85-87]. For example, one bioinspired method utilized the diatom as the $\mathrm{C}_{3} \mathrm{~N}_{4}$ formation templet, enlarging the specific surface area for enhanced light trapping and scattering and eventually high photocatalytic efficiency [27]. This research is mostly based on the slurry method. Optofluidics-based coenzyme regeneration appeared only in recent years.
Park et al. presented an optofluidic device that incorporated quantum dots and redox enzymes for photo-enzymatic synthesis [88]. As shown in Figure 8, the microchannel was separated into two parts by a valve, the light-dependent reaction zone for NADH regeneration in the upstream of microchannel and the light-independent zone for enzymatic synthesis in the downstream. Our group reported a optofluidic chip-based artificial PS I using a novel one-step fabrication method (see Figure 9), which outperformed the traditional methods in several aspects in terms of facile synthesis, promotion of the combination of g- $\mathrm{C}_{3} \mathrm{~N}_{4}$ and electron mediator through $\pi-\pi$ stacking, in addition to a significantly enhanced coenzyme regeneration rate [89]. Coenzyme regeneration is also of great importance in $\mathrm{CO}_{2}$ reduction with the help of enzymes. Formaldehyde dehydroge- 

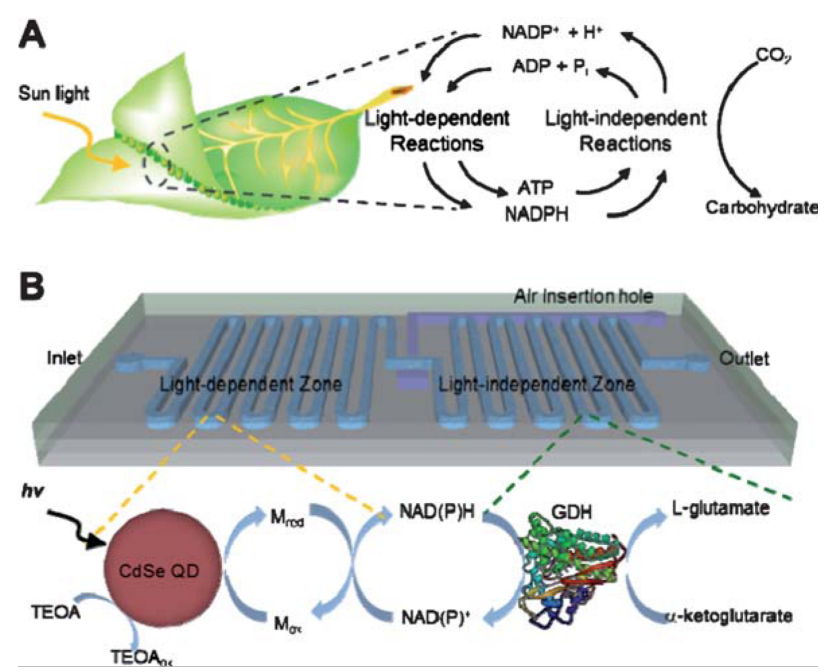

Figure 8: Microfluidic APS platform that incorporates quantum dots and redox enzymes for photoenzymatic synthesis. (A) Concept and (B) besign of microreactor in which the cofactor regeneration takes place in the light-dependent reaction zone and the enzymatic synthesis in the light-independent zone. Adapted from [88], copyright 2011 Royal Society of Chemistry.

A

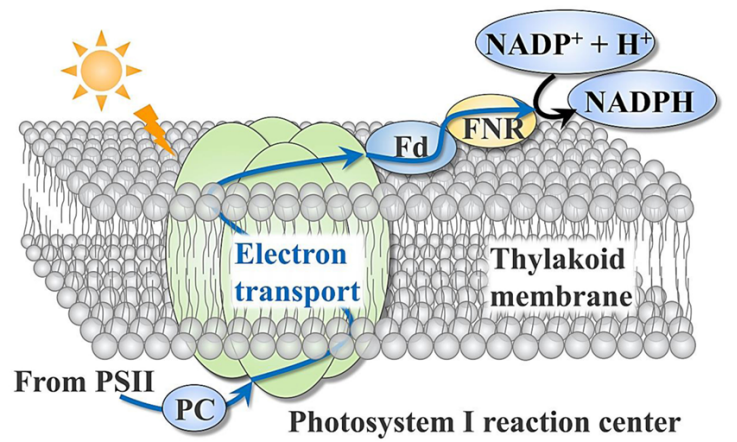

C

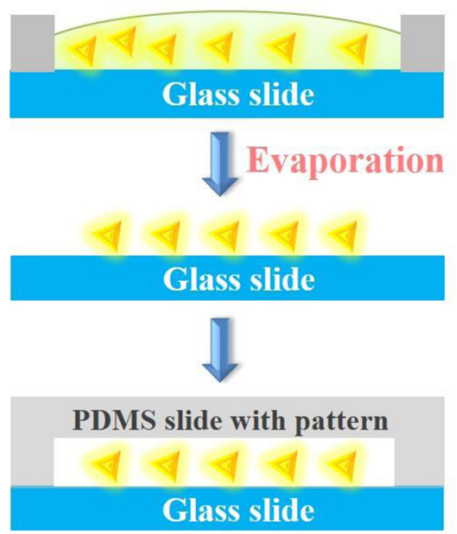

B

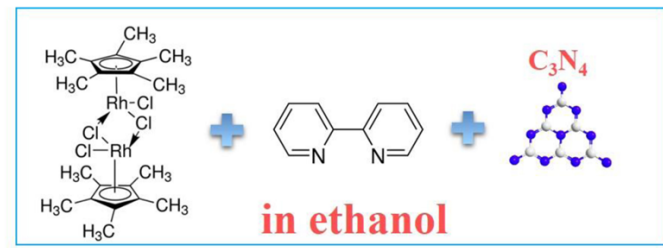

M formation

$\checkmark$ with $\mathrm{C}_{3} \mathrm{~N}_{4}$
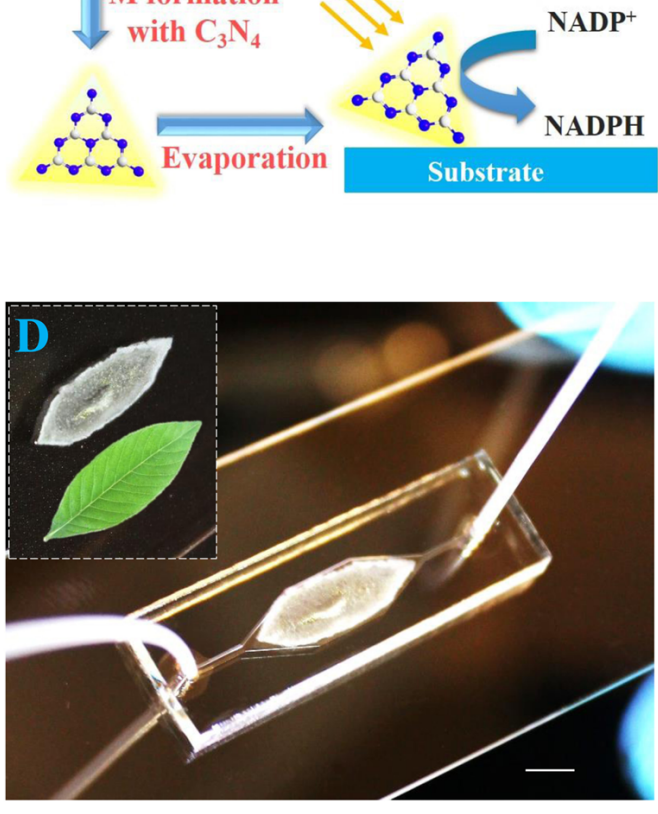

Figure 9: Microfluidic chip based artificial photosystem I. (A) Schematic illustration of the PS I reaction center. (B) One-step fabrication process of the immobilized artificial PS I (IAPSI) in the form of the $\mathrm{g}-\mathrm{C}_{3} \mathrm{~N}_{4}-\mathrm{M}$ film. (C) Simple procedures to fabricate the IAPSI microreactor. (D) Photograph of the as-fabricated IAPSI microreactor, in which the inset presents the leaf-like shape of $g-C_{3} N_{4}-M$. The scale bar is $2 \mathrm{~mm}$. Adapted from [89], copyright 2016 The Royal Society of Chemistry. 
nase is a typical one that selectively achieves methanol formation from $\mathrm{CO}_{2}$ with the depletion of NADH to $\mathrm{NAD}^{+}$[46]. The continuous regeneration of $\mathrm{NADH}$ enables the continuous reduction of $\mathrm{CO}_{2}$.

\section{Conclusion}

APS is a promising way to utilize solar energy and a prospective solution for the energy crisis, greenhouse effect and coenzyme utilization. An effective photocatalyst is expected to have wide-range absorption, long-term stability, fast electron-hole separation, and strong redox power. The heterojunction and $\mathrm{Z}$-scheme systems are the important most research results to date. Based on these systems, various materials have been developed for the improvement of photocatalytic efficiency [9094]. Besides, biomimetic or bioinspired strategies for the synthesis of semiconductor materials represents a significant advancement in the development of high-efficiency and costeffective visible-light photocatalysts for solar energy conversion [65-67]. Given the advantages of optofluidic systems, more studies with significant improvement are expected.

The optofluidic planar microreactor has shown to be a versatile platform for superior performance in water splitting, $\mathrm{CO}_{2}$ reduction and coenzyme regeneration. However, there are still some problems. One problem is the limited production amount caused by the small volume of the microreactor. For high throughput and adequate production, a feasible solution may involve the combination of two approaches: to parallelize the microreactors to form an array and to enlarge the microchannel in the lateral direction into a planar chamber [50,95-98]. Another problem is the lack of an integrated on-chip detection method. After the reaction, the production products should be collected and then analyzed by the bulky, expensive, traditional off-chip equipment, such as a UV-vis spectrometer or high-performance liquid chromatography and gas chromatography mass spectrometer. As demonstrated by our group in a work on microfluidic water purification [99], on-chip detection would make it convenient to monitor the reaction process in real time, to probe the intermediate reactions/productions and to study the reaction kinetics.

In view of the many merits induced by optofluidics, the microreactors may be also introduced to other APS systems such as nitrogen fixation (e.g., $\mathrm{NH}_{4}$ ) [100], $\mathrm{CH}_{4}$ [101-106], $\mathrm{CO}$ [107-111], formaldehyde [112,113], methanol [114-116], and formic acid [117]. More profound and meaningful work is expected to appear in the field of optofluidics-based APS since the optofluidic devices are versatile and can be integrated together with other functions, for instance, deoxygenation, temperature control, electricity/magnetic field and pressure [118-121].

\section{Acknowledgements}

This work is supported by Shandong Province Natural Science Foundation (No. ZR2016BB15), The Youth Science Fund of Shandong Academy of Sciences (No. 2016QN006), National Natural Science Foundation of China (no. 61377068, no. 61361166004), Research Grants Council of Hong Kong (N_PolyU505/13, PolyU 5334/12E, PolyU 152184/15E, PolyU 509513 and PolyU 152127/17E), and Hong Kong Polytechnic University (grants G-YN07, G-YBBE, G-YBPR, 4-BCAL, 1-ZVAW, 1-ZE14, A-PM21, 1-ZE27 and 1-ZVGH).

\section{ORCID ${ }^{\circledR}$ iDs}

Xuming Zhang - https://orcid.org/0000-0002-9326-5547

\section{References}

1. Turek, A. K.; Hardee, D. J.; Ullman, A. M.; Nocera, D. G.; Jacobsen, E. N. Angew. Chem., Int. Ed. 2016, 55, 539. doi:10.1002/anie.201508060

2. Solis, B. H.; Maher, A. G.; Dogutan, D. K.; Nocera, D. G.; Hammes-Schiffer, S. Proc. Natl. Acad. Sci. U. S. A. 2016, 113, 485. doi:10.1073/pnas.1521834112

3. Liu, C.; Colón, B. C.; Ziesack, M.; Silver, P. A.; Nocera, D. G. Science 2016, 352, 1210. doi:10.1126/science.aaf5039

4. Lin, S.; Diercks, C. S.; Zhang, Y.-B.; Kornienko, N.; Nichols, E. M.; Zhao, Y.; Paris, A. R.; Kim, D.; Yang, P.; Chang, C. J.; Yaghi, O. M. Science 2015, 349, 1208-1213. doi:10.1126/science.aac8343

5. Dou, L.; Wong, A. B.; Yu, Y.; Lai, M.; Kornienko, N.; Eaton, S. W.; Fu, A.; Bischak, C. G.; Ma, J.; Ding, T.; Ginsberg, N. S.; Wang, L.-W.; Alivisatos, A. P.; Yang, P. Science 2015, 349, 1518. doi:10.1126/science.aac7660

6. Nocera, D. G. Acc. Chem. Res. 2017, 50, 616. doi:10.1021/acs.accounts.6b00615

7. Zhou, H.; Yan, R.; Zhang, D.; Fan, T. Chem. - Eur. J. 2016, 22, 9870. doi:10.1002/chem.201600289

8. Tachibana, Y.; Vayssieres, L.; Durrant, J. R. Nat. Photonics 2012, 6, 511. doi:10.1038/nphoton.2012.175

9. Marshall, J. Nature 2014, 510, 22. doi:10.1038/510022a

10. Gust, D.; Moore, T. A.; Moore, A. L. Acc. Chem. Res. 2009, 42, 1890. doi:10.1021/ar900209b

11. Lin, S.; Liu, Y.; Hu, Z.; Lu, W.; Hin Mak, C.; Zeng, L.; Zhao, J.; Li, Y.; Yan, F.; Hong Tsang, Y.; Zhang, X.; Ping Lau, S. Nano Energy 2017, 42, 26-33. doi:10.1016/j.nanoen.2017.10.038

12. Faunce, T.; Styring, S.; Wasielewski, M. R.; Brudvig, G. W.; Rutherford, A. W.; Messinger, J.; Lee, A. F.; Hill, C. L.; DeGroot, H.; Fontecave, M.; MacFarlane, D. R.; Hankamer, B.; Nocera, D. G.; Tiede, D. M.; Dau, H.; Hillier, W.; Wang, L.; Amal, R. Energy Environ. Sci. 2013, 6, 1074. doi:10.1039/c3ee40534f

13. Liu, C.; Gallagher, J. J.; Sakimoto, K. K.; Nichols, E. M.; Chang, C. J.; Chang, M. C. Y.; Yang, P. Nano Lett. 2015, 15, 3634. doi:10.1021/acs.nanolett.5b01254

14. Torella, J. P.; Gagliardi, C. J.; Chen, J. S.; Bediako, D. K.; Colón, B.; Way, J. C.; Silver, P. A.; Nocera, D. G. Proc. Natl. Acad. Sci. U. S. A. 2015, 112, 2337. doi:10.1073/pnas.1503606112

15. Kornienko, N.; Zhao, Y.; Kley, C. S.; Zhu, C.; Kim, D.; Lin, S.; Chang, C. J.; Yaghi, O. M.; Yang, P. J. Am. Chem. Soc. 2015, 137, 14129. doi:10.1021/jacs.5b08212 
16. Choi, K. M.; Kim, D.; Rungtaweevoranit, B.; Trickett, C. A.; Barmanbek, J. T. D.; Alshammari, A. S.; Yang, P.; Yaghi, O. M. J. Am. Chem. Soc. 2017, 139, 356. doi:10.1021/jacs.6b11027

17. Cao, Z.; Kim, D.; Hong, D.; Yu, Y.; Xu, J.; Lin, S.; Wen, X.; Nichols, E. M.; Jeong, K.; Reimer, J. A.; Yang, P.; Chang, C. J. J. Am. Chem. Soc. 2016, 138, 8120. doi:10.1021/jacs.6b02878

18. Kong, Q.; Kim, D.; Liu, C.; Yu, Y.; Su, Y.; Li, Y.; Yang, P. Nano Lett. 2016, 16, 5675. doi:10.1021/acs.nanolett.6b02321

19. Su, Y.; Liu, C.; Brittman, S.; Tang, J.; Fu, A.; Kornienko, N.; Kong, Q.; Yang, P. Nat. Nanotechnol. 2016, 11, 609. doi:10.1038/nnano.2016.30

20. Nichols, E. M.; Gallagher, J. J.; Liu, C.; Su, Y.; Resasco, J.; Yu, Y.; Sun, Y.; Yang, P.; Chang, M. C. Y.; Chang, C. J. Proc. Natl. Acad. Sci. U. S. A. 2015, 112, 11461. doi:10.1073/pnas.1508075112

21. Kornienko, N.; Sakimoto, K. K.; Herlihy, D. M.; Nguyen, S. C.; Alivisatos, A. P.; Harris, C. B.; Schwartzberg, A.; Yang, P. Proc. Natl. Acad. Sci. U. S. A. 2016, 113, 11750. doi:10.1073/pnas.1610554113

22. Chen, M.-Y.; Zhuo, G.-Y.; Chen, K.-C.; Wu, P.-C.; Hsieh, T.-Y.; Liu, T.-M.; Chu, S.-W. BMC Plant Biol. 2014, 14, 175. doi:10.1186/1471-2229-14-175

23. Michelet, L.; Zaffagnini, M.; Morisse, S.; Sparla, F.; Pérez-Pérez, M. E.; Francia, F.; Danon, A.; Marchand, C. H.; Fermani, S.; Trost, P.; Lemaire, S. D. Front. Plant Sci. 2013, 4, 470. doi:10.3389/fpls.2013.00470

24. Hisatomi, T.; Kubota, J.; Domen, K. Chem. Soc. Rev. 2014, 43, 7520. doi:10.1039/C3CS60378D

25. Liu, J.; Liu, Y.; Liu, N.; Han, Y.; Zhang, X.; Huang, H.; Lifshitz, Y.; Lee, S.; Zhong, J.; Kang, Z. Science 2015, 347, 970. doi:10.1126/science.aaa3145

26. Liu, C.; Dasgupta, N. P.; Yang, P. Chem. Mater. 2014, 26, 415. doi: $10.1021 / \mathrm{cm} 4023198$

27. Liu, J.; Antonietti, M. Energy Environ. Sci. 2013, 6, 1486. doi:10.1039/c3ee40696b

28. Ma, K.; Yehezkeli, O.; Park, E.; Cha, J. N. ACS Catal. 2016, 6, 6982. doi:10.1021/acscatal.6b02524

29. Su, J.; Vayssieres, L. ACS Energy Lett. 2016, 1, 121. doi:10.1021/acsenergylett.6b00059

30. Kim, D.; Sakimoto, K. K.; Hong, D.; Yang, P. Angew. Chem., Int. Ed. 2015, 54, 3259. doi:10.1002/anie.201409116

31. Gemoets, H. P. L.; Su, Y.; Shang, M.; Hessel, V.; Luque, R.; Noël, T. Chem. Soc. Rev. 2016, 45, 83. doi:10.1039/C5CS00447K

32. Lin, Y.; Yuan, G.; Liu, R.; Zhou, S.; Sheehan, S. W.; Wang, D. Chem. Phys. Lett. 2011, 507, 209. doi:10.1016/j.cplett.2011.03.074

33. Lee, S. H.; Kim, J. H.; Park, C. B. Chem. - Eur. J. 2013, 19, 4392. doi:10.1002/chem.201204385

34. Maciá-Agulló, J. A.; Corma, A.; Garcia, H. Chem. - Eur. J. 2015, 21, 10940. doi:10.1002/chem.201406437

35. Whipple, D. T.; Finke, E. C.; Kenis, P. J. A. Electrochem. Solid-State Lett. 2010, 13, B109. doi:10.1149/1.3456590

36. Chen, R.; Li, L.; Zhu, X.; Wang, H.; Liao, Q.; Zhang, M.-X. Energy 2015, 83, 797. doi:10.1016/j.energy.2015.02.097

37. Simms, R.; Dubinsky, S.; Yudin, A.; Kumacheva, E. Lab Chip 2009, 9 , 2395. doi:10.1039/b904962b

38. Oelgemöller, M.; Shvydkiv, O. Molecules 2011, 16, 7522. doi:10.3390/molecules16097522

39. Psaltis, D.; Quake, S. R.; Yang, C. Nature 2006, 442, 381. doi:10.1038/nature05060
40. Elvira, K. S.; Casadevall i Solvas, X.; Wootton, R. C. R.; de Mello, A. J. Nat. Chem. 2013, 5, 905. doi:10.1038/nchem.1753

41. Erickson, D.; Sinton, D.; Psaltis, D. Nat. Photonics 2011, 5, 583. doi:10.1038/nphoton.2011.209

42. Shvydkiv, O.; Yavorskyy, A.; Tan, S. B.; Nolan, K.; Hoffmann, N.; Youssef, A.; Oelgemöller, M. Photochem. Photobiol. Sci. 2011, 10, 1399. doi:10.1039/c1pp05024a

43. Coyle, E. E.; Oelgemöller, M. Photochem. Photobiol. Sci. 2008, 7, 1313. doi:10.1039/b808778d

44. Zhao, D.; He, Z.; Wang, G.; Wang, H.; Zhang, Q.; Li, Y. Sens. Actuators, B 2016, 229, 281. doi:10.1016/j.snb.2016.01.125

45. Ji, X.; Su, Z.; Wang, P.; Ma, G.; Zhang, S. Small 2016, 12, 4753. doi:10.1002/smll.201600707

46. Yadav, R. K.; Oh, G. H.; Park, N.-J.; Kumar, A.; Kong, K.-j.; Baeg, J.-O. J. Am. Chem. Soc. 2014, 136, 16728. doi:10.1021/ja509650r

47. Godfray, H. C. J.; Beddington, J. R.; Crute, I. R.; Haddad, L.; Lawrence, D.; Muir, J. F.; Pretty, J.; Robinson, S.; Thomas, S. M.; Toulmin, C. Science 2010, 327, 812. doi:10.1126/science.1185383

48. Blankenship, R. E.; Tiede, D. M.; Barber, J.; Brudvig, G. W.; Fleming, G.; Ghirardi, M.; Gunner, M. R.; Junge, W.; Kramer, D. M.; Melis, A.; Moore, T. A.; Moser, C. C.; Nocera, D. G.; Nozik, A. J.; Ort, D. R.; Parson, W. W.; Prince, R. C.; Sayre, R. T. Science 2011, 332, 805. doi:10.1126/science.1200165

49. Whitesides, G. M. Nature 2006, 442, 368. doi:10.1038/nature05058

50. Wang, N.; Zhang, X.; Chen, B.; Song, W.; Chan, N. Y.; Chan, H. L. W. Lab Chip 2012, 12, 3983. doi:10.1039/c2lc40428a

51. Wang, N.; Zhang, X.; Wang, Y.; Yu, W.; Chan, H. L. W. Lab Chip 2014, 14, 1074. doi:10.1039/c3lc51233a

52. Gorkin, R.; Park, J.; Siegrist, J.; Amasia, M.; Lee, B. S.; Park, J.-M.; Kim, J.; Kim, H.; Madou, M.; Cho, Y.-K. Lab Chip 2010, 10, 1758. doi:10.1039/b924109d

53. Zhao, C.; Xie, Y.; Mao, Z.; Zhao, Y.; Rufo, J.; Yang, S.; Guo, F.; Mai, J. D.; Huang, T. J. Lab Chip 2014, 14, 384. doi:10.1039/c3lc50748c

54. Zhang, H.; Wang, J.-J.; Fan, J.; Fang, Q. Talanta 2013, 116, 946. doi:10.1016/j.talanta.2013.08.012

55. Sun, M.; Fang, Q. Lab Chip 2010, 10, 2864. doi:10.1039/c005290f

56. Su, Y.; Zhu, Y.; Fang, Q. Lab Chip 2013, 13, 1876. doi:10.1039/c3lc00063j

57. Li, Y.; Lin, B.; Ge, L.; Guo, H.; Chen, X.; Lu, M. Sci. Rep. 2016, 6, 28803. doi:10.1038/srep28803

58. Huang, X.; Hui, W.; Hao, C.; Yue, W.; Yang, M.; Cui, Y.; Wang, Z. Small 2014, 10, 758. doi:10.1002/smll.201202659

59. Huang, X.; Yue, W.; Liu, D.; Yue, J.; Li, J.; Sun, D.; Yang, M.; Wang, Z. Sci. Rep. 2016, 6, 23591. doi:10.1038/srep23591

60. Squires, T. M.; Quake, S. R. Rev. Mod. Phys. 2005, 77, 977. doi:10.1103/RevModPhys.77.977

61. Huang, X.; Zhu, Y.; Zhang, X.; Bao, Z.; Lei, D. Y.; Yu, W.; Dai, J.; Wang, Y. Sens. Actuators, B 2016, 222, 106. doi:10.1016/j.snb.2015.08.069

62. Liu, J.; He, K.; Wu, W.; Song, T.-B.; Kanatzidis, M. G. J. Am. Chem. Soc. 2017, 139, 2900. doi:10.1021/jacs.6b13279

63. Das, A. A. K.; Esfahani, M. M. N.; Velev, O. D.; Pamme, N.; Paunov, V. N. J. Mater. Chem. A 2015, 3, 20698. doi:10.1039/C5TA07112G

64. Li, S.; Yang, L.; Ola, O.; Maroto-Valer, M.; Du, X.; Yang, Y. Energy Convers. Manage. 2016, 116, 184. doi:10.1016/j.enconman.2016.03.001 
65. Sun, J.; Zhang, J.; Zhang, M.; Antonietti, M.; Fu, X.; Wang, X. Nat. Commun. 2012, 3, 1139. doi:10.1038/ncomms2152

66. Zhou, H.; Li, P.; Liu, J.; Chen, Z.; Liu, L.; Dontsova, D.; Yan, R.; Fan, T.; Zhang, D.; Ye, J. Nano Energy 2016, 25, 128. doi:10.1016/j.nanoen.2016.04.049

67. Tong, Z.; Yang, D.; Li, Z.; Nan, Y.; Ding, F.; Shen, Y.; Jiang, Z. ACS Nano 2017, 11, 1103. doi:10.1021/acsnano.6b08251

68. Zhou, P.; Yu, J.; Jaroniec, M. Adv. Mater. 2014, 26, 4920. doi:10.1002/adma.201400288

69. Cheng, L.; Zheng, Y.; Xu, Q.; Qin, Y. Adv. Opt. Mater. 2017, 5, 1600623. doi:10.1002/adom.201600623

70. Wang, L.; Liu, S.; Wang, Z.; Zhou, Y.; Qin, Y.; Wang, Z. L. ACS Nano 2016, 10, 2636. doi:10.1021/acsnano.5b07678

71. Tan, F.; Wang, N.; Lei, D. Y.; Yu, W.; Zhang, X. Adv. Opt. Mater. 2017, 5, 1600399. doi:10.1002/adom.201600399

72. Tan, F.; Li, T.; Wang, N.; Lai, S. K.; Tsoi, C. C.; Yu, W.; Zhang, X. Sci. Rep. 2016, 6, 33049. doi:10.1038/srep33049

73. Ahsan, S. S.; Gumus, A.; Erickson, D. Lab Chip 2013, 13, 409. doi:10.1039/C2LC41129F

74. Li, L.; Chen, R.; Liao, Q.; Zhu, X.; Wang, G.; Wang, D. Int. J. Hydrogen Energy 2014, 39, 19270. doi:10.1016/j.ijhydene.2014.05.098

75. Li, L.; Wang, G.; Chen, R.; Zhu, X.; Wang, H.; Liao, Q.; Yu, Y. Lab Chip 2014, 3368. doi:10.1039/c4lc00595c

76. Cheng, X.; Chen, R.; Zhu, X.; Liao, Q.; He, X.; Li, S.; Li, L. Int. J. Hydrogen Energy 2016, 41, 2457. doi:10.1016/j.ijhydene.2015.12.066

77. Chen, R.; Cheng, X.; Zhu, X.; Liao, Q.; An, L.; Ye, D.; He, X.; Wang, Z. Chem. Eng. J. 2017, 316, 911. doi:10.1016/j.cej.2017.02.044

78. Cheng, M.; Yang, S.; Chen, R.; Zhu, X.; Liao, Q.; Huang, Y. Int. J. Hydrogen Energy 2017, 42, 9722. doi:10.1016/j.ijhydene.2017.01.126

79. Sakimoto, K. K.; Wong, A. B.; Yang, P. Science 2016, 351, 74. doi:10.1126/science.aad3317

80. Thomas, A.; Fischer, A.; Goettmann, F.; Antonietti, M.; Müller, J.-O.; Schlögl, R.; Carlsson, J. M. J. Mater. Chem. 2008, 18, 4893. doi:10.1039/b800274f

81. Lee, M.; Kim, J. H.; Lee, S. H.; Lee, S. H.; Park, C. B. ChemSusChem 2011, 4, 581. doi:10.1002/cssc.201100074

82. Ryu, J.; Lee, S. H.; Nam, D. H.; Park, C. B. Adv. Mater. 2011, 23, 1883. doi:10.1002/adma.201004576

83. Lee, S. H.; Ryu, J.; Nam, D. H.; Park, C. B. Chem. Commun. 2011, 47, 4643. doi:10.1039/c0cc05246a

84. Liu, J.; An, T.; Chen, Z.; Wang, Z.; Zhou, H.; Fan, T.; Zhang, D.; Antonietti, M. J. Mater. Chem. A 2017, 5, 8933. doi:10.1039/C7TA02923C

85. Liu, J.; Cazelles, R.; Chen, Z. P.; Zhou, H.; Galarneau, A.; Antonietti, M. Phys. Chem. Chem. Phys. 2014, 16, 14699. doi:10.1039/c4cp01348d

86. Liu, J.; Huang, J.; Zhou, H.; Antonietti, M. ACS Appl. Mater. Interfaces 2014, 6, 8434. doi:10.1021/am501319v

87. Liu, J.; Wang, H.; Antonietti, M. Chem. Soc. Rev. 2016, 45, 2308. doi:10.1039/C5CS00767D

88. Lee, J. S.; Lee, S. H.; Kim, J. H.; Park, C. B. Lab Chip 2011, 11, 2309. doi:10.1039/c1lc20303g

89. Huang, X.; Liu, J.; Yang, Q.; Liu, Y.; Zhu, Y.; Li, T.; Tsang, Y. H.; Zhang, X. RSC Adv. 2016, 6, 101974. doi:10.1039/C6RA21390A

90. Chen, X.; Li, N.; Kong, Z.; Ong, W.-J.; Zhao, X. Mater. Horiz. 2018, in press. doi:10.1039/c7mh00557a
91. Kibria, M. G.; Mi, Z. J. Mater. Chem. A 2016, 4, 2801 doi:10.1039/C5TA07364B

92. Kumar, S.; Kumar, A.; Bahuguna, A.; Sharma, V.; Krishnan, V. Beilstein J. Nanotechnol. 2017, 8, 1571. doi:10.3762/bjnano.8.159

93. Ong, W.-J. Front. Mater. 2017, 4, No. 11. doi:10.3389/fmats.2017.00011

94. Ong, W.-J.; Tan, L.-L.; Ng, Y. H.; Yong, S.-T.; Chai, S.-P. Chem. Rev. 2016, 116, 7159. doi:10.1021/acs.chemrev.6b00075

95. Lei, L.; Wang, N.; Zhang, X. M.; Tai, Q.; Tsai, D. P.; Chan, H. L. W. Biomicrofluidics 2010, 4, 43004. doi:10.1063/1.3491471

96. Liao, W.; Wang, N.; Wang, T.; Xu, J.; Han, X.; Liu, Z.; Zhang, X.; Yu, W. Biomicrofluidics 2016, 10, 014123. doi:10.1063/1.4942947

97. Wang, N.; Tan, F.; Wan, L.; Wu, M.; Zhang, X. Biomicrofluidics 2014, 8, 054122. doi:10.1063/1.4899883

98. Wang, N.; Lei, L.; Zhang, X. M.; Tsang, Y. H.; Chen, Y.; Chan, H. L. W. Microelectron. Eng. 2011, 88, 2797. doi:10.1016/j.mee.2010.12.051

99. Wang, N.; Tan, F.; Zhao, Y.; Tsoi, C. C.; Fan, X.; Yu, W.; Zhang, X. Sci. Rep. 2016, 6, 28928. doi:10.1038/srep28928

100.Liu, J.; Kelley, M. S.; Wu, W.; Banerjee, A.; Douvalis, A. P.; Wu, J.; Zhang, Y.; Schatz, G. C.; Kanatzidis, M. G. Proc. Natl. Acad. Sci. U. S. A. 2016, 113, 5530. doi:10.1073/pnas.1605512113

101.Bi, F.; Ehsan, M. F.; Liu, W.; He, T. Chin. J. Chem. 2015, 33, 112. doi:10.1002/cjoc.201400476

102.Li, M.; Li, P.; Chang, K.; Wang, T.; Liu, L.; Kang, Q.; Ouyang, S.; Ye, J. Chem. Commun. 2015, 51, 7645. doi:10.1039/c5cc01124h

103. Marcì, G.; García-López, E. I.; Palmisano, L. Catal. Commun. 2014, 53, 38. doi:10.1016/j.catcom.2014.04.024

104.Vaiano, V.; Iervolino, G.; Sarno, G.; Sannino, D.; Rizzo, L.; Murcia Mesa, J. J.; Hidalgo, M. C.; Navío, J. A. Oil Gas Sci. Technol. 2015, 70, 891. doi:10.2516/ogst/2014062

105.Wu, T.; Zou, L.; Han, D.; Li, F.; Zhang, Q.; Niu, L. Green Chem. 2014, 16, 2142. doi:10.1039/C3GC42454E

106.Zhu, S.; Liang, S.; Tong, Y.; An, X.; Long, J.; Fu, X.; Wang, X. Phys. Chem. Chem. Phys. 2015, 17, 9761. doi:10.1039/C5CP00647C

107.Bonin, J.; Robert, M.; Routier, M. J. Am. Chem. Soc. 2014, 136, 16768. doi:10.1021/ja510290t

108.Deng, X.-Q.; Zhu, B.; Li, X.-S.; Liu, J.-L.; Zhu, X.; Zhu, A.-M. Appl. Catal., B: Environ. 2016, 188, 48. doi:10.1016/j.apcatb.2016.01.055

109. Fei, H.; Sampson, M. D.; Lee, Y.; Kubiak, C. P.; Cohen, S. M. Inorg. Chem. 2015, 54, 6821. doi:10.1021/acs.inorgchem.5b00752

110. Hwang, S.; Lee, M. C.; Choi, W. Appl. Catal., B: Environ. 2003, 46, 49. doi:10.1016/S0926-3373(03)00162-0

111.Zhang, Y.; Luc, W.; Hutchings, G. S.; Jiao, F. ACS Appl. Mater. Interfaces 2016, 8, 24652. doi:10.1021/acsami.6b09095

112. Nakata, K.; Ozaki, T.; Terashima, C.; Fujishima, A.; Einaga, Y. Angew. Chem., Int. Ed. 2014, 53, 871. doi:10.1002/anie.201308657

113.Tu, W.; Zhou, Y.; Zou, Z. Adv. Mater. 2014, 26, 4607. doi:10.1002/adma.201400087

114.Ma, Y.; Wang, X. L.; Jia, Y. S.; Chen, X. B.; Han, H. X.; Li, C. Chem. Rev. 2014, 114, 9987. doi:10.1021/cr500008u

115. Qin, S.; Xin, F.; Liu, Y.; Yin, X.; Ma, W. J. Colloid Interface Sci. 2011, 356, 257. doi:10.1016/j.jcis.2010.12.034

116.Zeng, G.; Qu, J.; Li, Z.; Pavaskar, P.; Cronin, S. B. ACS Catal. 2014, 4, 3512. doi:10.1021/cs500697w

117.Li, K.; An, X.; Park, K. H.; Khraisheh, M.; Tang, J. Catal. Today 2014, 224, 3. doi:10.1016/j.cattod.2013.12.006 
118.Chiang, M.-Y.; Hsu, Y.-W.; Hsieh, H.-Y.; Chen, S.-Y.; Fan, S.-K. Sci. Adv. 2016, 2, e1600964. doi:10.1126/sciadv.1600964

119.Wang, L.; Liu, W.; Wang, Y.; Wang, J.-C.; Tu, Q.; Liu, R.; Wang, J. Lab Chip 2013, 13, 695. doi:10.1039/c2lc40661f

120.Dunkel, P.; Hayat, Z.; Barosi, A.; Bchellaoui, N.; Dhimane, H.; Dalko, P. I.; El Abed, A. I. Lab Chip 2016, 16, 1484 doi:10.1039/c6lc00024j

121.Ngo, H. M.; Lai, N. D.; Ledoux-Rak, I. Nanoscale 2016, 8, 3489. doi:10.1039/C5NR07571H

\section{License and Terms}

This is an Open Access article under the terms of the Creative Commons Attribution License

(http://creativecommons.org/licenses/by/4.0), which permits unrestricted use, distribution, and reproduction in any medium, provided the original work is properly cited.

The license is subject to the Beilstein Journal of

Nanotechnology terms and conditions:

(http://www.beilstein-journals.org/bjnano)

The definitive version of this article is the electronic one which can be found at: doi:10.3762/bjnano.9.5 